\title{
Falling prevalence of smoking: how low can we go?
}

Simon Chapman

\section{A sustained international initiative to fund major public awareness campaigns in nations that could never afford to run such campaigns would make a huge difference to nations in which such awareness remains rudimentary}

$\mathrm{H}$ ow low might the prevalence of smoking fall in whole nations? Countries that have the lowest prevalence of smoking for both sexes combined are mostly those with strong cultural proscriptions against smoking by women. The NationMaster site (http:// www.nationmaster.com), sourcing data from the World Health Organization, shows 44 nations where reported prevalence of smoking among women is $<10 \%$, 28 nations where it is $<5 \%$ and 12 nations where it is $<2 \%$ (Qatar reports that $0.5 \%$ women smoke). Very low smoking rates among women, which generally owe nothing to public health policies, can pull down the combined prevalence rate of smoking among men and women to levels well below those in nations where prevalence of smoking among women has been high, but has fallen. There are few, if any, strategic lessons for public health in examining most nations with very low prevalence of smoking among women in the hope of seeing a policy blueprint.

If large falls in the prevalence of smoking are the main consideration, there are four front-runners for the title of world's most successful smoking control nation: Canada, Australia, USA and Sweden (table 1).

Sweden has attained the lowest prevalence of smoking among any nation, largely because of the major shift that has occurred from smoking to snus use in men: another $20 \%$ of men and $2 \%$ of women use snus daily, but do not smoke. ${ }^{1}$ At the state level, low daily smoking rates

in California, USA $(9.8 \%),{ }^{4}$ New South Wales, Australia $(13.9 \%)^{5}$ and British Columbia, Canada $(11 \%)^{6}$ stand out. For several years in the 1990s, California hosted the world's best-funded tobacco control programme and pioneered smoke-free public places, which reduced both the frequency and prevalence of smoking. Utah, USA, with a large Mormon population, has an $11.5 \%$ smoking rate ${ }^{4}$ but there are few practical implications in this for other populations.

\section{How reliable are the data?}

There are important concerns about the reliability of survey methods in determining true rates of smoking in communities. Some subpopulations with high smoking rates are never included in estimates of national smoking. These include prisoners (in the USA in mid-2005, there were 2186230 people in US jails-about $1 \%$ of the adult population ${ }^{7}$ ), the homeless, ${ }^{8}$ illegal immigrants, people in mental health institutions, people who do not speak the language of the country in which surveys are being conducted and poor people living in remote areas with no telephone.

Also, rates are more likely to be underreported as response rates to surveys decline, particularly when conducted by telephone. Technological advances (increased use of cell phones, use of answering machines to screen unwanted calls and caller identification) have caused increases in under-reporting. The US Market Research and Intelligence

Table 1 World's most successful smoking control nations

\begin{tabular}{llll}
\hline $\begin{array}{l}\text { Country, age range in } \\
\text { years, (year) }\end{array}$ & Daily smoking (\%) & \multicolumn{2}{l}{ Less than daily smoking } \\
$(\%)$ & Notal smoking (\%) \\
\hline Sweden, $\geqslant 16(2002)^{1}$ & NS & 4 & 16 \\
Canada, $>15(2006)^{2}$ & 14 & 3.2 & 18 \\
Australia, $>14(2004)^{3}$ & 17.4 & 4 & 20.6 \\
USA, $>18(2005)^{4}$ & 16.9 & & 20.9 \\
\hline NS, not stated. & & &
\end{tabular}

Association reports that refusal rates to one-off telephone surveys increased from $66 \%$ in 1995 to $78 \%$ in $2002 .{ }^{9}$ According to the California Tobacco Surveys, response rates fell from $70 \%$ in $1992-3$ to $51.1 \%$ in 1998-9. ${ }^{10}$ However, one study comparing estimates obtained from the US Current Population Survey, which uses expensive door-to-door interviewing and obtains significantly higher response rates than phone surveys, showed that "under or over-representation of population subgroups has not changed as response rates have declined". ${ }^{10}$

Together, these considerations combine to suggest an underclass of hidden smokers who may collectively add several percentage points onto "official" rates of smoking prevalence in communities.

In Australia, between 1991 and 2004, the prevalence of smoking (daily+weekly) fell from $27.1 \%$ to $19.0 \%$, a fall of $8.1 \%$ in absolute terms, averaging $0.58 \%$ per year, and representing a $29.9 \%$ fall in relative terms from the 1991 level. In the 5 years 1991-5, the prevalence of smoking fell on average by $0.34 \%$ per year, but in the most recent 7 years (1998-2004) when mass reach campaigning was boosted, the decline nearly doubled to $0.66 \%$ per year. ${ }^{3}$ If this later rate continues, smoking would theoretically reach zero prevalence in 29 years, in 2034.

But is this realistic? Indeed, might it be too pessimistic a forecast? Will smoking ever disappear or will it reach some low level somewhere $<10 \%$ and remain there? Optimists would argue that there are strong grounds for suggesting that the decline we are now seeing in nations addressing smoking issues will accelerate even faster. One 1998 US projection, built on reducing youth smoking initiation from $30 \%$ to $20 \%$, forecast that no more than one-eighth of the US population $(12.5 \%)$ would eventually smoke, even if cessation rates did not decrease. ${ }^{11}$

The current Californian "gold standard" of $9.8 \%$ daily prevalence of smoking might be one benchmark. But why not strive for the levels reached by various subpopulations as an "art of the possible" reference point? Doctors in the US and Australia have long had reported prevalence rates $<3 \%{ }^{12}{ }^{13}$ driven presumably by peer and community expectations and their constant encounters with the harms of smoking. Warner and Burns ${ }^{14}$ argue "whether the hard core is best represented by the $2.1 \%$ of pregnant college graduates who continue to smoke, $3 \%$ of physicians, $6.4 \%$ of college-educated Californians, or $8.5 \%$ of Americans with postgraduate degrees, the majority of the $36.4 \%$ of blue-collar workers who smoke cannot reasonably be categorized as hard core" and have a long way to go before 
standard tried-and-true tobacco control strategies fail to deliver more ex smokers.

In Australia, recent sustained declines in smoking among youth (smoking among youth has never been lower) ${ }^{15}$ will see smaller cohorts of new smokers entering calculations of prevalence of smoking in the next decade. There would seem to be no coherent case for forecasting any slowing of the current cessation rate.

When the time comes that less than one in ten of the community smoke, and these continue to express almost universal regret about having started, ${ }^{16}$ the dynamics of smoking may change considerably from those operating today when nations "doing well" have more like one in five smoking. The increasing denormalisation of public smoking is likely to infect politicians as well, making them more receptive to "finishing the job" on tobacco control by mopping up remaining inconsistencies in comprehensive policy and less anxious about offending ever-diminishing portions of the electorate.

High smoking subpopulation smoking rates in all but the most impoverished nations are highest among those who have had the least education and are in the lowest socioeconomic groups. Although many countries might be doing well by international standards, smoking among low socioeconomic subpopulations typically shows a very different picture. For example, compared with the highest educated and income-earning quintile in Australia, those in the lowest have odds ratios for smoking of 1.69 (for education) and 1.43 (for income). ${ }^{17}$ Smoking duration from onset to cessation is $38 \%$ longer for those earning under $\$ 300$ than for those earning over $\mathrm{A} \$ 800$ a week. Those with $<10$ years of education smoked for $13 \%$ longer than those with $>12$ years of education. ${ }^{18}$ Indigenous Australians have a prevalence of smoking of $54 \% .{ }^{19}$ Australian single mothers are more than twice as likely to smoke as mothers with partners. ${ }^{20}$ People with mental health problems are about twice as likely to smoke than those without any history of mental health problems. ${ }^{21}$

There are two broad analyses of what might be done about these disparities. The first argues that disparities in the prevalence of smoking mirror broad societal socioeconomic disparities and that the differential between high and low socioeconomic segments of the population will not narrow until societies become more egalitarian on wider indices such as income distribution and educational opportunity. In such analyses, particularly when applied to subpopulations with multiple social and health disadvantages, smoking is seen as something unlikely to yield much to "single risk-factor" interventions. Qualitative research has often shown that people living in poverty smoke to relieve stress and as a sort of "holiday" from hopelessness. ${ }^{22}$

The second analysis emphasises that while smoking is much more prevalent in low-income groups and other disadvantaged populations, in many nations it remains the case that a minority of the very poor do not smoke, and that characterising the poverty/low education nexus with smoking as a kind of inevitability is inaccurate and also underestimates such groups' responsiveness to the same factors that have reduced smoking in all social strata.

\section{More precise targeting?}

Subpopulation disparities stimulate calls for campaign money to be fractured into a series of different "targeted" campaigns designed to better appeal to different sex, age, sexual orientation and (most often) socioeconomic, racial and ethnic groups. The argument runs that important cultural differences in each of these groups cause smoking to be phenomenologically different from its role and meaning in other groups. "One size fits all" standard approaches to motivating cessation are therefore said to be insensitive, ill-conceived and bound not to work

However, it is worth reflecting on whether the tobacco industry-in trying to promote smoking-conceives of the challenge in the same way. Although the tobacco industry certainly does nuance many of its promotional efforts to make them more appealing to particular subpopulations, ${ }^{23}{ }^{24}$ it rarely develops or succeeds in selling major brands exclusively to such groups. Major brand advertising and packaging is largely and increasingly globalised, suggesting that industry marketing intelligence believes that appeals are universal. There are no differences in the packaging for Marlboro, Camel or Mild Seven in different nations. Where advertising continues, it too is largely uniform and not fractured into major promotions for each of the many different cultural groups that make up multicultural societies today.

Moreover, research shows that different racial and socioeconomic groups respond equally well to quit campaigns. A recent analysis showed that declines in the prevalence of smoking among African Americans from 1992 to 2002 showed no differences across US states, despite differing degrees of targeted smokingcessation activity between states. ${ }^{25}$ Efforts to fracture limited campaign budgets into multiple smaller, targeted campaigns will have many in the health promotion professional community cheering these on, but the cost will inevitably be a greatly diluted ability to mount the necessary large campaigns directed at the whole population of smokers.

Large public awareness campaigns to inform and motivate millions of smokers about quitting seems destined to remain a feature of everyday life in wealthier nations. However, very few poorer nations can afford to even get to the starting line with such campaigns and try in vain to inform their communities via valiant, low-budget efforts at publicity on World No Tobacco Day. A sustained international initiative to fund major public awareness campaigns in nations that could never afford to run such campaigns would make a huge difference to nations in which such awareness remains rudimentary. The profligacy of some areas of tobacco control expenditure in some industrialised nations is embarrassing when there are now many more smokers and deaths caused by smoking in less developed nations.

Tobacco Control 2007; 16:145-147.

doi: 10.1136/tc.2007.021220

Correspondence to: Professor S Chapman School of Public Health, University of Sydney, Edward Ford Building A27, Sydney, NSW 2006, Australia; sc@med.usyd.edu.au

Competing interests: None declared.

\section{REFERENCES}

1 Ramstrom LM, Foulds J. Role of snus in initiation and cessation of tobacco smoking in Sweden. Tob Control 2006:15:210-14.

2 Health Canada. Canadian Tobacco Use Monitoring Survey. Ottawa, Canada: Health Canada, 2005;

3 Australian Institute of Health and Welfare. 2004 National Drug Strategy Household Survey: detailed findings. Drug statistics series. Canberra: AlHW 2005.

4 Centers for Disease Control and Prevention Behavioral Risk Factor Surveillance Systemprevalence data - tobacco use 2005. Columbia, USA Centers for Disease Control and Prevention, 2005.

5 New South Wales Department of Health. Centre for Epidemiology and Research, NSW Population Health Survey 2006 (HOIST) 2007. http:// tobacco.health.usyd.edu.au/site/supersite/ resources/pdfs/DailyYear02-06.pdf.

6 Health Canada. Canadian Tobacco Use Monitoring Survey (CTUMS) 2006. Ottawa, Canada: Health Canada, 2006.

7 Harrison PM, Beck AJ. Prison and jail inmates at midyear 2005. Washington, DC: Bureau of Justice Statistics Bulletin (US Department of Justice, Office of Justice Programs), 2006:1-13.

8 Okuyemi KS, Caldwell AR, Thomas JL, et al. Homelessness and smoking cessation: insights from focus groups. Nicotine Tob Res 2006;8:287-96.

9 Allen M, Ambrose D, Halpenny G, et al. Telephone refusal rate still rising. Results of the 2002 Response Rate Survey. Ontario, Canada: Marketing Research and Intelligence Association, 2003.

10 Biener L, Garrett CA, Gilpin EA, et al. Consequences of declining survey response rates for smoking prevalence estimates. Am J Prev Med 2004:27:254-7.

11 Mendez D, Warner KE, Courant PN. Has smoking cessation ceased? Expected trends in the 
prevalence of smoking in the United States. Am J Epidemiol 1998;148:249-58.

12 Nelson DE, Giovino GA, Emont SL, et al. Trends in cigarette smoking among US physicians and nurses. JAMA 1994:271:1273-5.

13 Young JM, Ward JE. Declining rates of smoking among medical practitioners. Med J Aust 1997; 167:232.

14 Warner KE, Burns DM. Hardening and the hardcore smoker: concepts, evidence, and implications. Nicotine Tob Res 2003;5:37-48.

15 White V, Hayman J. Smoking behaviours of Australian secondary school students 2005. Carlton: Centre for Behavioural Research in Cancer, The Cancer Council Victoria, 2006.

16 Fong GT, Hammond D, Laux FL, et al. The nearuniversal experience of regret among smokers in four countries: findings from the International
Tobacco Control Policy Evaluation Survey. Nicotine Tob Res 2004;6(Suppl 3):S341-51.

17 Siahpush M, Borland R. Socio-demographic variations in smoking status among Australians aged $>$ or $=18$ : multivariate results from the 1995 National Health Survey. Aust NZ J Public Health 2001;25:438-42.

18 Siahpush M, Heller G, Singh G. Lower levels of occupation, income and education are strongly associated with a longer smoking duration: multivariate results from the 2001 Australian National Drug Strategy Survey. Public Health 2005; 1 19:1 105-10.

19 Ivers RG. An evidence-based approach to planning tobacco interventions for Aboriginal people. Drug Alcohol Rev 2004;23:5-9.

20 Siahpush $\mathbf{M}$. Why is lone-motherhood so strongly associated with smoking? Aust NZ J Public Health 2004:28:37-42.
21 Lasser K, Boyd JW, Woolhandler S, et al. Smoking and mental illness: a population-based prevalence study. JAMA 2000;284:2606-10.

22 Stewart MJ, Brosky G, Gillis A, et al. Disadvantaged women and smoking. Can J Public Health 1996;87:257-60.

23 Smith EA, Offen N, Malone RE. What makes an ad a cigarette ad? Commercial tobacco imagery in the lesbian, gay, and bisexual press. J Epidemiol Community Health 2005;59:1086-91.

24 Balbach ED, Gasior RJ, Barbeau EM. R.J. Reynolds targeting of African Americans: 1988-2000, Am J Public Health 2003:93:822-7.

25 Trinidad DR, Messer K, Gilpin EA, et al. The Californian Tobacco Control Program's effect on adult smoking. 3: Similar effects for AfricanAmericans across states, Tob Control 2007;16:96-100.

\section{The Lighter Side}
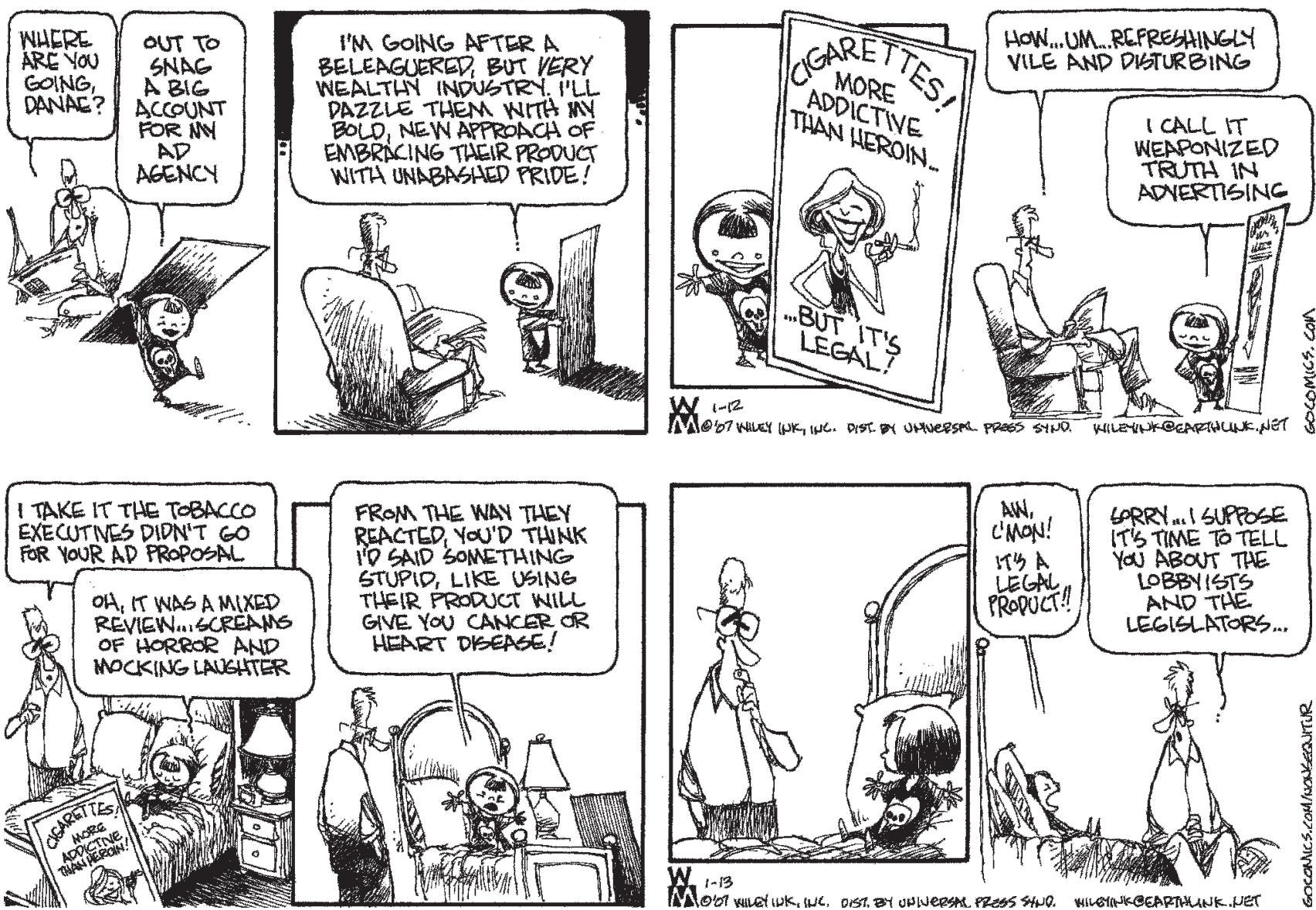

Non Sequitur $\odot 2007$ Wiley Miller. Distributed by Universal Press Syndicate. Reprinted with permission. All rights reserved. 